\title{
Short- and Mid-Term Changes in Lung Function after Bilateral Pulmonary Metastasectomy
}

\author{
Stefan Welter ${ }^{1}$ Danjouma Cheufou ${ }^{1}$ Mahmood Zahin ${ }^{1}$ Sandra Kampe ${ }^{2}$ Kaid Darwiche ${ }^{3}$ \\ Gerhard Weinreich ${ }^{3}$ Georgios Stamatis ${ }^{1}$
}

${ }^{1}$ Department of Thoracic Surgery, Ruhrlandklinik, Essen, Germany

${ }^{2}$ Department of Anaesthesiology, Ruhrlandklinik, Essen, Germany

${ }^{3}$ Department of Pneumology, Ruhrlandklinik, Essen, Germany
Address for correspondence Stefan Welter, MD, Department of Thoracic Surgery, Ruhrlandklinik, Tueschener Weg 40, Essen 45239, Germany (e-mail: stefan.we@t-online.de).

Thorac Cardiovasc Surg 2016;64:139-145.

\begin{abstract}
Keywords

- metastasectomy

- lung function

- bilateral metastasectomy

- functional impairment

Introduction The resection of pulmonary metastases is associated with a loss of lung function. The amount of functional impairment after bilateral metastasectomy remains unclear. Because only around $35 \%$ of those patients may expect long-term survival, it is important to preserve enough pulmonary function for an adequate quality of life. This analysis of 31 bilaterally operated patients was performed to describe the amount of pulmonary function loss.

Methods This is a post-hoc subanalysis and comparison of a population that was published before. All pulmonary metastasectomies were performed through an anteroaxillary thoracotomy in all patients. Resections were performed with staplers, electrocautery, or laser. All patients had pulmonary function tests (PFTs) preoperative and after 3 months at the follow-up visit, including spirometry, diffusing capacity of lung for carbon monoxide (Dıco) and blood gases. Of the 31 bilaterally operated cases, 15 had additional PFTs after each staged operation before discharge from hospital.

Results Altogether, 271 nodules (median 7, mean 8.2) were removed from the 31 patients with a lobectomy in 2, a segmentectomy in 8 , and multiple wedge resections in 21 patients, with this being the largest resection. The mean loss of pulmonary function at follow-up visit was forced vital capacity (FVC) $-15.2 \%$, total lung capacity (TLC) - 13.8\%, forced expiratory volume in 1 second $\left(\mathrm{FEV}_{1}\right)-16.3 \%$, and Dıco $-10.3 \%$, all of which were significant $(p=<$ 0.001). The 15 patients with PFTs after each operation showed a stepwise decrease of volume parameters and Dico with deepest values after the second surgery of around $--40 \%$ from preoperative values. At this time, $\mathrm{PO}_{2}$ was also significantly reduced by $10 \mathrm{~mm} \mathrm{Hg}(p=0.01)$. Comparing the bilateral group with 86 patients after unilateral metastasectomy, we found significantly more nodules removed in the bilateral group (8.2 vs. 3.1; $p<0.001)$ and that the loss of volume parameters was twice that of the unilateral group after metastasectomy. Dico impairment did not differ between the groups ( -10.3 vs. $-9.5 \% ; p=0.868$ ) after 3 months. Conclusion Midterm pulmonary function impairment after bilateral pulmonary metastasectomy is $15 \%$ of spirometry values and $10 \%$ of Dıco. Reduction of spirometry values is almost twice compared with the group after unilateral surgery. Early functional loss after the second intervention causes FVC, TLC, and FEV 1 reduction of around $40 \%$ and is associated with lower $\mathrm{PO}_{2}(-10 \mathrm{~mm} \mathrm{Hg})$. Therefore, bilateral metastasectomy can be offered to patients who do not have greater pulmonary limitations.
\end{abstract}

received

January 14, 2014 accepted after revision

April 25, 2014

published online

July 28, 2014 (c) 2016 Georg Thieme Verlag KG Stuttgart · New York
DOI http://dx.doi.org/ 10.1055/s-0034-1383828. ISSN 0171-6425. 


\section{Introduction}

The resection of lung metastases is a well-accepted method to treat oligometastases from a wide range of primary tumors. The postoperative loss of pulmonary function has been described for wedge resections ${ }^{1,2}$ and anatomical resections $\mathrm{s}^{3,4}$ and can be predicted to a certain extent. Postoperative chemotherapy and bilateral surgery were recently reported to be a risk factor for impaired function, ${ }^{5}$ but the extent of functional loss in the bilateral surgery group remains unclear. Knowledge of functional loss is of particular importance because many patients have impaired cardiopulmonary reserve after several cycles of chemotherapy, due to increased age or comorbidities. Furthermore, only 25 to $35 \%$ of patients receiving metastasectomy can expect long-term survival; thus, metastasectomy should not be debilitating and sufficient pulmonary function should remain for an adequate quality of life. ${ }^{6-9}$ In a previous analysis, ${ }^{1}$ we found that $5 \%$ of the pulmonary functional impairment may be attributed to thoracotomy. Therefore, one may hypothesize that bilateral thoracotomy causes a significant deterioration in pulmonary function, which is twice the loss following unilateral intervention. To prove this hypothesis, we performed a post-hoc subanalysis of the previously analyzed collective of 117 prospectively evaluated patients ${ }^{1}$ and compared standardized spirometric values and Dıco before and after metastasectomy of the unilateral with the bilateral resected patients.

\section{Methods}

This study was performed as a post-hoc subanalysis of a prospective observational case series that was previously published. ${ }^{5}$ The subset of patients with bilateral metastasectomy was further analyzed and a second comparative analysis of the unilateral versus bilateral operated patients was performed. From April 2008 to April 2010, patients from the Department of Thoracic Surgery who were scheduled for pulmonary metastasectomy were prospectively included in this study. Patients with a planned complete removal of lung metastases were asked for written consent the day before surgery. The study protocol was approved by our hospital's review board. The Eastern Cooperative Oncology Group (ECOG) performance state of all patients was 0 or 1 and no significant cardiorespiratory limitations were noted preoperatively. All metastasectomies were performed via an anteroaxillary muscle-saving thoracotomy with thoracotomy being used for the systematic palpation of the entire lung. Bilateral metastases were removed simultaneously or staged within 6 weeks. Lung resection was performed at the surgeon's discretion with staplers, electrocautery, or laser, and was supplemented by lymph node sampling. One or two drains were placed before closing the thoracotomy. All patients received analgesia based on the hospital's standard protocol, which included peridural anesthesia whenever possible. ${ }^{10} \mathrm{~A}$ standard physiotherapy program was used to support expiratory flow, lung expansion, and coughing.

\section{Pulmonary Function Testing}

Standard pulmonary function tests (PFTs) and Dico were measured preoperatively ( $\mathrm{t} 1$ ) and postoperatively the day before discharge ( $\mathrm{t} 2$ ). Patients with a sequential bilateral metastasectomy were measured again after the second intervention ( $t 3$ ). All cases had a planned follow-up evaluation 3 months after the last resection (t4). Spirometry tests were performed using a ZAN 500 Body Plethysmograph equipped with a ZAN 200 SB CO-Diffusion module (Spire Health Ltd., Hertford, UK) according to the criteria of the American Thoracic Society. The measurements were taken after administering a bronchodilator. The Dıco was measured using the single-breath method. The FVC, TLC, FEV ${ }_{1}$, DLco, and diffusion coefficient for carbon monoxide (KCO) were expressed as percentages of the predicted values for age, gender, and height, according to the European Community for Steel and Coal (ECCS) prediction equations.$^{11}$

\section{Evaluation}

Lung function parameters, blood gas values, and the percentage of carbon monoxide diffusion capacity before and after metastasectomy and at follow-up were entered into a database along with the number of resections, the type of resection, and the laterality of the resection.

\section{Statistical Analysis}

All variables were analyzed by the methods of descriptive statistics (frequency, mean \pm standard deviation, range). To test differences between means, the Student $t$-test was applied in the case of normal distribution; otherwise, the Mann-Whitney $U$ test was used. To discriminate between normal and non-normal distributed variables, the Kolmogorov-Smirnov test was applied. Levene test was used to assess the equality of variance in different samples. We applied the chi-square test or the Fisher exact test to compare frequencies and proportions in two groups. We considered $p<0.05$ to be statistically significant. Statistical analysis was performed with SPSS 20.0 (SPSS Inc., Chicago, United States).

\section{Results}

Altogether, 117 patients completed the follow-up visit and could be further analyzed; 86 of these patients had unilateral and 31 had bilateral resections. Twenty one of the bilaterally operated patients were males. Fifteen of these 31 patients had complete PFTs at $\mathrm{t} 1$ and $\mathrm{t} 4$ and after both sequential operations $(t 2, t 3)$ before discharge from hospital. Information about PFTs at $\mathrm{t} 2$ or $\mathrm{t} 3$ was incomplete for 16 patients. The overall mortality of the initially enrolled study population corresponding to the whole study period was $3 / 162(1.8 \%)$ and was published earlier. ${ }^{5}$

\section{Characteristics of the Bilateral Group}

Altogether, 271 nodules (median 7, mean 8.2) were removed from the 31 patients with lobectomy in 2, segmentectomy in 8 , and multiple wedge resection in 21 patients, with this being the largest resection. Postoperative complications potentially affecting pulmonary function were noticed in two 
Table 1 Mean values of pulmonary function tests before and 3 months after bilateral pulmonary metastasectomy

\begin{tabular}{|c|c|c|c|c|c|}
\hline \multirow[t]{2}{*}{ Parameter } & \multirow[t]{2}{*}{$n=$} & Preoperative & Follow-up & Difference & Significance \\
\hline & & t1 (min-max) & $\mathrm{t} 4$ & $(\mathrm{t} 4-\mathrm{t} 1)(\mathrm{SD})$ & $(\mathrm{t} 4-\mathrm{t} 1)$ \\
\hline FVC (\%) & 31 & $97.8(70-126)$ & 82.7 & $-15.1(13.1)$ & $<0.001$ \\
\hline TLC (\%) & 31 & $96.3(73-130)$ & 82.4 & $-13.9(14.8)$ & $<0.001$ \\
\hline $\mathrm{FEV}_{1}(\%)$ & 31 & $89.7(59-120)$ & 73.5 & $-16.3(11.5)$ & $<0.001$ \\
\hline $\mathrm{FEV}_{1} / \mathrm{FVC}$ & 31 & $72.8(48-92)$ & 70.8 & $-2.1(9.2)$ & 0.856 \\
\hline Dıco (\%) & 24 & $83.6(36-115)$ & 70.2 & $-10.7(14.6)$ & $<0.001$ \\
\hline KCO (\%) & 24 & $72.3(39-100)$ & 72.7 & $0.4(10.3)$ & 0.407 \\
\hline $\mathrm{Po}_{2} \mathrm{~mm} \mathrm{Hg}$ & 31 & $79.3(65-97)$ & 81.2 & $1.1(11.9)$ & 0.347 \\
\hline $\mathrm{PCO}_{2} \mathrm{~mm} \mathrm{Hg}$ & 31 & $38.1(29-44)$ & 38.7 & $0.6(3.8)$ & 0.446 \\
\hline $\mathrm{AaDO}_{2} \mathrm{~mm} \mathrm{Hg}$ & 31 & $21.9(4-48)$ & 20.3 & $1.6(8.9)$ & 0.416 \\
\hline
\end{tabular}

Abbreviations: $\mathrm{AaDO}_{2}$, alveoloarterial oxygen tension difference; Dıco, diffusing capacity of lung for carbon monoxide FEV ${ }_{1}$, forced expiratory volume in 1 second; FVC, forced vital capacity; SD, standard deviation; TLC, total lung capacity.

Notes: In 7 of 31 patients, Dıco and KCO were not available either preoperatively or postoperatively so the difference could not be calculated. Significances were calculated for the differences between follow-up pulmonary function values and preoperative values.

cases (6.5\%) with diaphragmatic elevation and two cases (6.5\%) receiving pleurodesis for prolonged air leak. The mean time between the two operations was 28 days; four patients had a simultaneous bilateral metastasectomy. The mean time from the date of first operation to the follow-up visit was 4.4 months. The mean loss of pulmonary function at the follow-up visit compared with preoperative values was significant for all volume measures and for Dico between 13 and $16 \%(-$ Table $\mathbf{1})$. No changes were found between preoperative and follow-up values for $\mathrm{FEV}_{1} / \mathrm{FVC}, \mathrm{PO}_{2}, \mathrm{PcO}_{2}$, and $\mathrm{KCO}$. The stepwise deterioration of PFT values was calculated using the complete dataset of the 15 patients who had PFTs after each metastasectomy before discharge from hospital and is depicted in - Fig. 1 with the corresponding values shown in - Table 2. All volume measures demonstrated a significant stepwise deterioration after the first and second interventions with a significant reduction in $\mathrm{PO}_{2}$ noticed after each

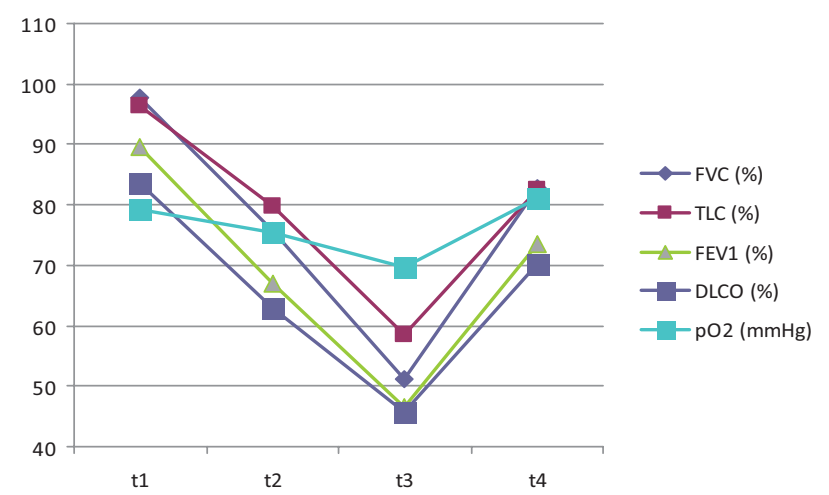

Fig. 1 Predicted pulmonary function values of bilaterally operated patients at different times. Legend 1: Values were taken from the 15 patients with complete PFTs at $\mathrm{t} 1$-t4. The $y$-axis represents percentage (\%) of the corresponding PFT value. Dıco, diffusing capacity of lung for carbon monoxide $\mathrm{FEV}_{1}$, forced expiratory volume in 1 second; FVC, forced vital capacity; TLC, total lung capacity. operation (- $4.0 \mathrm{~mm} \mathrm{Hg}$ [t2] and further $-5.7 \% \mathrm{~mm} \mathrm{Hg}$ [t3], $p=0.01$ ), such that $\mathrm{Po}_{2}$ was almost $10 \mathrm{~mm} \mathrm{Hg}$ lower after the second intervention compared with preoperative $\mathrm{PO}_{2}$. $\mathrm{KCO}$ and $\mathrm{PCO}_{2}$ remained unchanged at all times. Partial recovery was registered at follow-up for all volume measures and Dıco compared with $\mathrm{t} 3$ measures, along with complete normalization of $\mathrm{Po}_{2}$.

\section{Characteristics of the Unilateral Group}

Altogether, 266 nodules (median 2, mean 3.1) were removed from the 86 patients, with lobectomy in 11 , segmentectomy in 17, and wedge excision in 58 patients, with this being the largest resection. The mean time from the date of first operation to the follow-up visit was 3.8 months. Postoperative complications potentially affecting pulmonary function were noticed in six cases $(7.0 \%)$ with diaphragmatic elevation and two cases $(2.3 \%)$ receiving pleurodesis for prolonged air leak. A small subgroup of $13(15.1 \%)$ patients had $\mathrm{FEV}_{1}$ values less than $70 \%$ and were thus impaired preoperatively. The loss of $\mathrm{FEV}_{1}$ at the follow-up visit was a mean of 5.5\% (- 20 to $+10 \%)$. The other characteristics of the two groups are depicted in -Table 3.

\section{Comparison of the Uni- and Bilateral Groups}

The two groups did not differ in terms of age $(p=0.331)$, preoperative chemotherapy ( $p=0.306)$, number of segmentectomies $(p=0.177)$, preoperative spirometry values (FVC $[p=0.930], \quad$ TLC $[p=0.200], \quad \operatorname{FEV}_{1} \quad[p=0.398]$, DıCO $[p=0.916]$, КСО $[p=0.596], \mathrm{Po}_{2}[p=0.868]$, and $\mathrm{PCO}_{2}$ $[p=0.459]$ ), or the frequency of post-thoracotomy pain syndrome (unilateral vs. bilateral, 6.5 vs. $12.8 \%$ ), or detected tumor recurrence (unilateral vs. bilateral, 11.8 vs. $19.4 \%$ ) at follow-up. Similar rates were found in both groups for continuous use of pain medication (unilateral vs. bilateral, 15.3 vs. $16.1 \%$ ) and postoperative chemotherapy (unilateral vs. bilateral, 17.6 vs. $19.4 \%$ ) at follow-up. There was a trend for more adhesions to be removed in the unilateral group, with 
Table 2 Spirometry values at different times with significance of changes $(n=15)$

\begin{tabular}{|c|c|c|c|c|}
\hline \multirow[t]{2}{*}{ Parameter } & Preoperative & Postoperative 1 & Postoperative 2 & Follow-up \\
\hline & $\mathrm{t} 1$ & t2 $(\operatorname{sig} 1)$ & t3 $(\operatorname{sig} 2)$ & t4 (sig 4) \\
\hline FVC (\%) & 97.8 & $75.6(<0.001)$ & $51.3(0.001)$ & $82.7(<0.001)$ \\
\hline TLC (\%) & 96.3 & $79.7(<0.001)$ & $58.5(0.001)$ & $82.4(<0.001)$ \\
\hline $\mathrm{FEV}_{1}(\%)$ & 89.7 & $66.9(<0.001)$ & $46.5(0.001)$ & $73.5(<0.001)$ \\
\hline Dıco (\%) & 83.6 & $62.8(0.008)$ & $45.6(0.007)$ & $70.2(<0.001)$ \\
\hline KCO (\%) & 72.3 & $68.0(0.23)$ & $69.1(0.721)$ & $72.9(0.407)$ \\
\hline $\mathrm{Po}_{2} \mathrm{~mm} \mathrm{Hg}$ & 79.3 & $75.3(0.01)$ & $69.6(0.014)$ & $81.2(0.347)$ \\
\hline $\mathrm{PCO}_{2} \mathrm{~mm} \mathrm{Hg}$ & 38.1 & $37.7(0.20)$ & $37.8(0.905)$ & $38.7(0.446)$ \\
\hline
\end{tabular}

Abbreviations: Dıco, diffusing capacity of lung for carbon monoxide; FVC, forced vital capacity; $\mathrm{FEV}_{1}$, forced expiratory volume in 1 second; KCO, diffusion coefficient for carbon monoxide; TLC, total lung capacity.

Notes: Of 31 individuals with PFTs preoperatively and at follow-up, 15 had a complete set of values after the first and second metastasectomies. The statistical significance of differences between t1-t2 (sig 1), t2-t3 (sig 2), and t1-t4 (sig 4) was calculated.

29.1 versus $12.9 \%$ in the bilateral group $(p=0.091)$ ( - Table 3). The only terms that differed significantly between the groups were the cumulative number of resected specimens (mean 2.7 vs. $8.2 ; p<0.001$ ) ( - Table 3 ) and the relative functional loss of FVC (\%) $(p=0.004)$, TLC (\%) (0.004), and FEV1 (\%) $(p=0.001)$ at follow-up. Dico and $\mathrm{Po}_{2}$ went back to normal in both groups after 3 months ( - Table 4 ).

\section{Discussion}

Bilateral simultaneous or staged metastasectomy is a routine procedure to treat oligometastases from various primaries. ${ }^{8,12}$ Unfortunately, more than $60 \%$ of patients have a tumor relapse and only $36 \%$ will survive for more than 5 years. $6,9,13$ Metastasectomy is usually performed as a parenchyma-sparing precision resection, but can also include anatomical resections. Current selection criteria include sufficient pulmonary function to tolerate the planned resection. ${ }^{8,14}$ This tolerance is usually expressed when predicted postoperative function exceeds a certain lower limit. A significantly increased operative risk for complications was found when ppo (predicted post-operative) $\mathrm{FEV}_{1}$ was less than $1.0 \mathrm{~L},{ }^{15}$ or when preoperative Dico was reduced. ${ }^{16,17}$ Current guidelines advise excluding candidates from anatomic lung resection when ppo $\mathrm{FEV}_{1}$ and Duco are $<30$ to $40 \%$ of their predicted values. ${ }^{17-19}$ Thus, the prediction of postoperative preserved pulmonary function seems essential, even for metastasectomy candidates, especially those who have cardiopulmonary impairment. ${ }^{15,20}$ In terms of metastasectomy, patients are currently accepted for or denied these procedures based on the personal experience of the surgeon, rather than on the calculation of ppo pulmonary function. The loss of pulmonary function after metastasectomy is a topic of current interest, 2,5,21 but many details remain unclear, such as the functional loss after bilateral operations. Because pulmonary metastasectomy is noncurative in two-thirds of the patients, it is important not to look solely at operative risk, but to also include the goal of a mobile life free from oxygen dependence and therefore calculate and predict preserved postoperative pulmonary function.

\section{Current Study}

This post-hoc subanalysis was based on prospectively evaluated patients and was performed to define the average

Table 3 Comparison of treatment-related factors in the two groups

\begin{tabular}{|l|l|l|l|}
\hline Parameter & Unilateral group $(\boldsymbol{n}=\mathbf{8 6})$ & Bilateral group $(\boldsymbol{n}=\mathbf{3 1})$ & Significance \\
\hline Age & Mean 60.3 (SD 12.1) & Mean 57.1 (SD 14.8) & 0.331 \\
\hline Specimen & Mean 2.7 (SD 3.6) & Mean 8.2 (SD 5.4) & $<0.001$ \\
\hline Preoperative chemo & $16(18.6 \%)$ & $9(29 \%)$ & 0.306 \\
\hline Presence of adhesions & $37(43 \%)$ & $9(29 \%)$ & 0.202 \\
\hline Lobectomy & $11(12.8 \%)$ & $2(6.5 \%)$ & 0.509 \\
\hline PTS & $11(12.8 \%)$ & $2(6.5 \%)$ & 0.509 \\
\hline Continued pain med. & $13(15.3 \%)$ & $5(16.1 \%)$ & 1.000 \\
\hline Postoperative chemo & $15(17.6 \%)$ & $6(19.4 \%)$ & 1.000 \\
\hline Tumor recurrence & $10(11.8 \%)$ & $6(19.4 \%)$ & 0.362 \\
\hline
\end{tabular}

Abbreviations: PTS, postthoracotomy pain syndrome; SD, standard deviation.

Note: Significance $=$ bilateral significance with Pearson chi-square test, tumor recurrence evaluated at the follow-up visit after 3 months. 
Table 4 Mean differences of pulmonary function tests (follow-up-preoperative value) between the unilateral $(n=86)$ and the bilateral $(n=31)$ group $(\Delta \mathrm{t} 4-\mathrm{t} 1)$

\begin{tabular}{|c|c|c|c|}
\hline Parameter & Unilateral (SD) & Bilateral (SD) & Significance $(p)$ \\
\hline FVC (\%) & $-8.0(10.7)$ & $-15.1(13.1)$ & 0.004 \\
\hline TLC (\%) & $-7.0(10.9)$ & $-13.8(14.8)$ & 0.004 \\
\hline $\mathrm{FEV}_{1}(\%)$ & $-9.0(9.7)$ & $-16.3(11.5)$ & 0.001 \\
\hline $\mathrm{FEV}_{1} / \mathrm{FVC}$ & $-1.7(5.6)$ & $-2.1(9.2)$ & 0.556 \\
\hline Dıco (\%) & $-9.5(10.0)$ & $-10.3(14.6)$ & 0.868 \\
\hline KCO (\%) & $-0.7(8.8)$ & $0.4(10.3)$ & 0.502 \\
\hline $\mathrm{Po}_{2}(\mathrm{~mm} \mathrm{Hg})$ & $0.1(10.1)$ & 1.1 (11.9) & 0.550 \\
\hline $\mathrm{PCO}_{2}(\mathrm{~mm} \mathrm{Hg})$ & $0.6(7.0)$ & $0.6(3.8)$ & 0.346 \\
\hline $\mathrm{AaDo}_{2}(\mathrm{~mm} \mathrm{Hg})$ & $-0.6(9.0)$ & $-1.5(8.9)$ & 0.416 \\
\hline
\end{tabular}

Abbreviations: $\mathrm{AaDO}_{2}$, alveoloarterial oxygen tension difference; Dıco, diffusing capacity of lung for carbon monoxide; FVC, forced vital capacity; $\mathrm{FEV}_{1}$, forced expiratory volume in 1 second; KCO, diffusion coefficient for carbon monoxide; SD, standard deviation; TLC, total lung capacity. Note: The significance was calculated as the differences in $\Delta \mathrm{t} 4-\mathrm{t} 1$ between the two groups.

functional loss after bilateral metastasectomy, with the aim of enabling prediction of the function remaining after such interventions in the future. To the best of our knowledge, this study is the first detailed report about midterm loss of pulmonary function after bilateral metastasectomy and the first comparison of lung function changes after unilateral versus bilateral open pulmonary metastasectomy ( - Table 4$)$.

\section{Current Results}

Our results conflicted with our initially formulated hypothesis: first, the mean number of resected specimens per patient was 2.7 in the unilateral group and significantly more (8.2) in the bilateral group, which implies that bilateral manifestation is associated with a higher number of lesions per side. Furthermore, there was a trend for fewer adhesions in the group with bilateral metastasectomies. Second, whereas the functional impairment of the volume parameters FVC, TLC, and $\mathrm{FEV}_{1}$ in the bilateral group was significantly higher, almost double that of the unilateral group after metastasectomy, the changes in Duco did not differ significantly: - 9.5\% in the unilateral versus $-10.7 \%$ in the bilateral group $(p=0.868)$. The fact that Dıco after 3 months was higher than ppo Dıco was reported previously for lobectomy (+10\%) and pneumonectomy $(+17 \%)$ without pathophysiological explanation. ${ }^{22}$ The volume-adjusted diffusion index KCO did not change at all in either group, meaning that the effects of chemotherapy, infections, or other lung injuries cannot be used to explain the difference in Dcto. In both groups, blood gases returned to normal values after 3 months. Others also found unchanged KCO after resection. ${ }^{22}$

\section{Operative Access}

The influence of operative access was not investigated in our study because all patients had the same anteroaxillary incision. However, it is well known that operative access is an important predictor of postoperative function, with thoracoscopic interventions causing less impairment than sternotomy, and sternotomy causing less impairment than posterolateral thoracotomy. ${ }^{21}$ The effect of anteroaxillary thoracotomy may be responsible for a $5 \%$ restrictive disturbance of volume parameters. ${ }^{1}$

\section{Limitations of the Study}

This study has some limitations. It was conducted in a single center, where metastasectomy is a routine procedure. The sample size is rather small for a substantiated message; this is most evident at the high values of standard deviations. The operation was performed by different surgeons with different preferences for the use of laser, electrocautery, or stapler. As this might reflect the normal spectrum in the thoracic surgery community, however, it might not be a disadvantage. The amount of lung tissue removed was not quantified. Besides the fact that patients with lobectomies and segmentectomies were included into the analysis, it is unquestionable that small superficial nodules have been removed with less tissue than a deep wedge resection for a large nodule. To our understanding, this bias cannot be solved, but we think that the analysis of a heterogeneous population reflects the daily situation and can offer a certain impression of the results of bilateral resection for a patient. The study protocol with PFTs at $\mathrm{t} 1, \mathrm{t} 2, \mathrm{t} 3$, and $\mathrm{t} 4$ was completed in only 15 patients in the bilateral group, which is undoubtedly a limiting factor for further interpretation. However, the most interesting question, that is, which of the two interventions in the bilateral group is more harmful to pulmonary function, was addressed with the analysis of this small subgroup. We found a linear reduction of all volume parameters from preoperative (t 1 ) to $t 2$ and from $t 2$ to $t 3$, which can be attributed to the similar incision on both sides and comparable amounts of lung tissue resected on both sides. Nonetheless, the second intervention was worse for the patient, leading to the lowest values of volume parameters, at around $40 \%$ less than preoperative values, and a reduction in $\mathrm{Po}_{2}$ of $10 \mathrm{~mm} \mathrm{Hg}$. Subsequent pain management in this situation is even more important to reduce stress to a minimum and avoid complications. Within 3 months after $\mathrm{t} 3$, significant 
functional recovery occurred, back to higher values than measured after the first metastasectomy. However, the remaining functional impairment after 3 months exceeded that known for lobectomy in lung cancer treatment. ${ }^{22,23}$ Therefore, one can postulate that midterm pulmonary function changes after bilateral metastasectomy are less severe than the early changes after the first operation.

Despite the fact that the sample size was small, the statistical differences between the groups and different time points were highly significant and thus relevant. Also, because bilateral metastasectomy is a rare procedure, we feel that it is difficult to collect larger sample sizes within an adequate time period. Long-term results are difficult to obtain because many patients have tumor relapse and need further treatment, which affects pulmonary function and thus superimposes the effect of surgery. We believe that midterm results after 3 months are sufficient to describe the effect of metastasectomy on pulmonary function. One can assume that functional recovery occurs within 3 to 6 months postoperatively. Other authors found that pulmonary function recovery after lung resection reaches a plateau after 3 to 6 months. ${ }^{22,24}$ Bolliger et $\mathrm{al}^{23}$ investigated patients after lobectomy and found a functional loss for FVC, $\mathrm{FEV}_{1}$, TLC, and DLCo of $-10.7,-10.9$, -12.4 , and $-8.5 \%$, respectively, at 3 months with a further recovery at 6 months to $-7.3,-8.8,-10.2$, and $-4.0 \%$. This underlines our hypothesis that only minor functional improvement occurs after 3 months.

\section{Conclusion}

Because more than two-thirds of patients will develop tumor recurrence after pulmonary metastasectomy, a thorough consultation should include the expected functional impairment of the procedure. Bilateral interventions are associated with a three- to fourfold higher number of metastases which need to be resected. Impairment of pulmonary volume parameters is around 40\% early after the second operation, but recovers to a midterm loss of $15 \%( \pm 13)$ at 3 months when using anteroaxillary thoracotomy on both sides. Oxygen partial pressure is decreased by $10 \mathrm{~mm} \mathrm{Hg}$ after the second operation but normalizes completely after 3 months. However, to predict the postoperative function of a specific patient, one should bear in mind that the amount of tissue to be removed is different in every individual. Mean values from this study should only be used as an indication.

\section{References}

1 Welter S, Cheufou D, Sommerwerck U, Maletzki F, Stamatis G. Changes in lung function parameters after wedge resections: a prospective evaluation of a patient undergoing metastasectomy. Chest 2012;141:1482-1489

2 Petrella F, Chieco P, Solli P, et al. Which factors affect pulmonary function after lung metastasectomy? Eur J Cardiothorac Surg 2009; 35(5):792-796

3 Nakahara K, Monden Y, Ohno K, Miyoshi S, Maeda H, Kawashima Y. A method for predicting postoperative lung function and its relation to postoperative complications in patients with lung cancer. Ann Thorac Surg 1985;39(3):260-265
4 Wyser C, Stulz P, Solèr M, et al. Prospective evaluation of an algorithm for the functional assessment of lung resection candidates. Am J Respir Crit Care Med 1999;159(5 Pt 1): 1450-1456

5 Welter S, Cheufou D, Ketscher C, Darwiche K, Maletzki F, Stamatis G. Risk factors for impaired lung function after pulmonary metastasectomy: a prospective observational study of 117 cases. Eur J Cardiothorac Surg 2012;42(2):e22-e27

6 Pastorino U, Buyse M. Long-term results of lung metastasectomy: prognostic analyses based on 5206 cases. The International Registry of Lung Metastases. J Thorac Cardiovasc Surg 1997;113(1): 37-49

7 Schulte T, Schniewind B, Dohrmann P, Küchler T, Kurdow R. The extent of lung parenchyma resection significantly impacts longterm quality of life in patients with non-small cell lung cancer. Chest 2009;135(2):322-329

8 Rusch VW. Pulmonary metastasectomy: a moving target. J Thorac Oncol 2010;5(6, Suppl 2):S130-S131

9 Hornbech K, Ravn J, Steinbrüchel DA. Current status of pulmonary metastasectomy. Eur J Cardiothorac Surg 2011;39(6): 955-962

10 Kampe S, Lohmer J, Weinreich G, Hahn M, Stamatis G, Welter S. Epidural analgesia is not superior to systemic postoperative analgesia with regard to preventing chronic or neuropathic pain after thoracotomy. J Cardiothorac Surg 2013;8(1):127

11 Quanjer PH, Tammeling GJ, Cotes JE, Pedersen OF, Peslin R, Yernault JC; Official Statement of the European Respiratory Society. Lung volumes and forced ventilatory flows. Report Working Party Standardization of Lung Function Tests, European Community for Steel and Coal. Official statement of the European Respiratory Society. Eur Respir J Suppl 1993;16:5-40

12 Pfannschmidt J, Dienemann H, Hoffmann H. Surgical resection of pulmonary metastases from colorectal cancer: a systematic review of published series. Ann Thorac Surg 2007;84(1): 324-338

13 Rolle A, Pereszlenyi A, Koch R, Richard M, Baier B. Is surgery for multiple lung metastases reasonable? A total of 328 consecutive patients with multiple-laser metastasectomies with a new 1318nm Nd:YAG laser. J Thorac Cardiovasc Surg 2006;131(6): 1236-1242

14 Rusch VW. Pulmonary metastasectomy. Current indications. Chest 1995;107(6, Suppl):322S-331S

15 Kearney DJ, Lee TH, Reilly JJ, DeCamp MM, Sugarbaker DJ. Assessment of operative risk in patients undergoing lung resection. Importance of predicted pulmonary function. Chest 1994; 105(3):753-759

16 Ferguson MK, Little L, Rizzo L, et al. Diffusing capacity predicts morbidity and mortality after pulmonary resection. J Thorac Cardiovasc Surg 1988;96(6):894-900

17 Brunelli A, Refai MA, Salati M, Sabbatini A, Morgan-Hughes NJ, Rocco G. Carbon monoxide lung diffusion capacity improves risk stratification in patients without airflow limitation: evidence for systematic measurement before lung resection. Eur J Cardiothorac Surg 2006;29(4):567-570

18 Bolliger CT. Evaluation of operability before lung resection. Curr Opin Pulm Med 2003;9(4):321-326

19 Colice GL, Shafazand S, Griffin FP, Keenan R, Bolliger CT. Physiologic evaluation of the patient with lung cancer being considered for resectional surgery. ACCP Evidenced-Based Clinical Practice Guidelines (2nd Edition). Chest 2007;132:161S-177S

20 Brunelli A, Charloux A, Bolliger CT, et al; European Society of Thoracic Surgeons Joint Task Force on Fitness For Radical Therapy. The European Respiratory Society and European Society of Thoracic Surgeons clinical guidelines for evaluating fitness for radical treatment (surgery and chemoradiotherapy) in patients with lung cancer. Eur J Cardiothorac Surg 2009; 36(1):181-184 
21 Ninomiya M, Nakajima J, Tanaka M, et al. Effects of lung metastasectomy on respiratory function. Jpn J Thorac Cardiovasc Surg 2001;49(1):17-20

22 Brunelli A, Refai M, Salati M, Xiumé F, Sabbatini A. Predicted versus observed FEV1 and DLCO after major lung resection: a prospective evaluation at different postoperative periods. Ann Thorac Surg 2007;83(3):1134-1139
23 Bolliger CT, Jordan P, Solèr M, et al. Pulmonary function and exercise capacity after lung resection. Eur Respir J 1996;9(3): 415-421

24 Varela G, Brunelli A, Rocco G, et al. Predicted versus observed FEV1 in the immediate postoperative period after pulmonary lobectomy. Eur J Cardiothorac Surg 2006;30(4):644-648 